\title{
Design of EMI Filter for Boost PFC Circuit
}

\author{
Vijaya Vachak ${ }^{1}$, Anula Khare ${ }^{2}$, Amit Shrivatava ${ }^{3}$ \\ Electrical \& Electronics Engineering Department Oriental College of Technology, Bhopal, India
}

\begin{abstract}
Mains-connected boost power factor correction (PFC) circuits are employed in order to meet EMI standards. The EMI filter together with the boost inductor has to attenuate the high frequency (HF) voltage component to the mains side of the converter. In this paper, it is how the switching frequency and the relative ripple of the boost inductor current affect the filter and boost inductor volume and losses. With it, the optimum switching frequency and ratio of the ripple and fundamental current amplitude with respect to volume and losses are found. procedure for designing ac line EMI filters is presented. This procedure is based on the analysis of conducted EMI problems and the use of a noise separator.
\end{abstract}

Keywords: Electromagnetic interference (EMI), common mode noise, differential mode noise, Emi filter, boost converter, power factor, power factor correction circuit.

\section{Introduction}

Power electronic systems that are connected to the grid have to fulfill EMI standards concerning the level of DM EMI noise in the grid-side current, as e.g. Class A and Class B limits from CISPR. In order to meet such regulations, mains-connected boost power factor correction (PFC) circuits are employed. Together with an EMI input filter, they assure an approximate sinusoidal current waveform with power factors close to unity. A typical topology of a single-phase boost PFC rectifier is shown in Fig. 1(a). This topology has been discussed extensively in literature. Such systems are designed for high efficiency and high power density; however, the increase of the power density often affects the efficiency, i.e. a trade-off between these two quality indices exists . Depending on the application, the objectives efficiency and power density are weighted differently.[1]

In this paper, a procedure for designing EM1 filters for boost PFC circuit will be presented. This procedure is based on the analysis of conducted EM1 problems and the use of an EM1 diagnostic tool, noise separator, developed recently. The noise separator, constructed from a radio-frequency power splitter, can be used to separate differential-mode (DM) and common-mode (CM) noise. This greatly simplifies the filter design process. In the paper, a review of conducted EM1 problems will be given first. Factors affecting EM1 performance and issues of filter design will be described. [2]

Input EMI filters are used in conjunction with the power stage to reduce the noise generated by highfrequency switching operation in order to satisfy regulatory limits as defined in the U.S. Federal Communications Commission (FCC) Title 47 Code of Federal Regulations (CFR) Section 15 (USA), Europe's Comité International Spécial des Perturbations Radioélectriques (CISPR) 15 (Europe) and other equivalent regional standards.[3]

\section{Electromagnetic Interference}

The use of sophisticated electronic equipment has led to rapid increase in Electromagnetic Interference (EMI). EMI is in two forms- conducted and radiated, of which the term conducted emissions refers to the coupling of electromagnetic energy produced by equipment to its

power cord [1-3]. The conducted interference can further be classified into two types, namely common-mode and differential-mode.

A brief review of conducted EM1 measurement is important to the discussion of filter design to be described later.

\section{Continous Conduction Mode (CCM)}

The CCM operation is more popular at higher power levels as it has minimal peak and rms currents. In comparison with the CrM operation, the peak currents can be $50 \%$ lower and rms currents can be $25 \%$ lower. This reduce the stress in power FET, diode and inductor. In addition, the filtering is easier as the current through the boost inductor is more continuous.

\section{Common-Mode (Cm) Noise And Differential-Mode (Dm) Noise}

$\mathrm{CM}$ noise current flows in the same direction on both power conductors and returns via the ground conductor and can be suppressed by the use of inductors within an EMI filter that are placed connected from 
both low current flows through one suppressed by the filter connected in parallel between noises exist as shown in Figure 1.

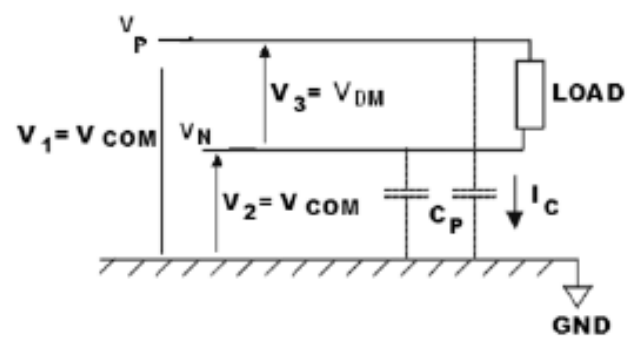

Figure 1: Common-mode and differential-mode noise.

Common mode noise is given as:

$$
\mathrm{V}_{\mathrm{cm}}=\frac{\mathrm{V}_{\mathrm{P}}+\mathrm{V}_{\mathrm{N}}}{2}
$$

And differential noise is given as

$$
\mathrm{V}_{\mathrm{dm}}=\frac{\mathrm{V}_{\mathrm{P}}-\mathrm{V}_{\mathrm{N}}}{2}
$$

where, VP is phase voltage and VN is neutral voltage. The capacitors $\mathrm{C}_{\mathrm{p}}$ are connected in shunt to the power lines to reduce CM noise and in order to reduce DM noise capacitors should be connected across the power line.

\section{Emi Filters}

EMI filtering circuits are employed so that the end product complies with the applicable EMC standards. Among the most frequently cited EMC standards are EN55022 or it equivalent CISPR 22 standard for IT equipment, EN55011 for industrial equipment.

Table 1: CISPR 22 Conducted Emissions Limits for Class A Devices

\begin{tabular}{|l|l|l|}
\hline Frequency $(\mathrm{MHz})$ & $\mu \mathrm{V} \mathrm{QP}(\mathrm{AV})$ & $\mathrm{dB}(\mu \mathrm{V}) \mathrm{QP}(\mathrm{AV})$ \\
\hline $0.15-0.5$ & $8912.5(1995)$ & $79(66)$ \\
\hline $0.5-30$ & $4467(1000)$ & $73(60)$ \\
\hline
\end{tabular}

Table 2: CISPR 22 Conducted Emission Limits for Class B Devices

\begin{tabular}{|l|l|l|}
\hline Frequency $(\mathrm{MHz})$ & $\mu \mathrm{V} \mathrm{QP}(\mathrm{AV})$ & $\mathrm{dB}(\mu \mathrm{V}) \mathrm{QP}(\mathrm{AV})$ \\
\hline $0.15-0.5$ & $1995-631(631-199.5)$ & $66-56(56-46)($ limit varies linearly) \\
\hline $0.5-5$ & $631(199.5) 56(46)$ & $5-301000(316) 60(50)$ \\
\hline
\end{tabular}

The frequency limits for conducted emissions are shown in Table 1 and Table 2. Conducted emissions are regulated by CISPR over the frequency range from $150 \mathrm{KHz}-30 \mathrm{MHz}$ [10-12]. If the emissions are found to exceed the limits specified by EMC standards, then EMI filter would be designed in order to reduce the noise produced by the equipment under test.

\section{Filter Design}

The basic setup shown in Figure2 consists of Line Impedance Stabilization Network (LISN), Equipment under Test (EUT) which is a 2-transistor SMPS circuit, mains power supply and a noise separator circuit.

\section{Filter Design}

The basic setup shown in Figure2 consists of Line Impedance Stabilization Network (LISN), Equipment under Test (EUT) which is a 2-transistor SMPS circuit, mains power supply and a noise separator circuit. 


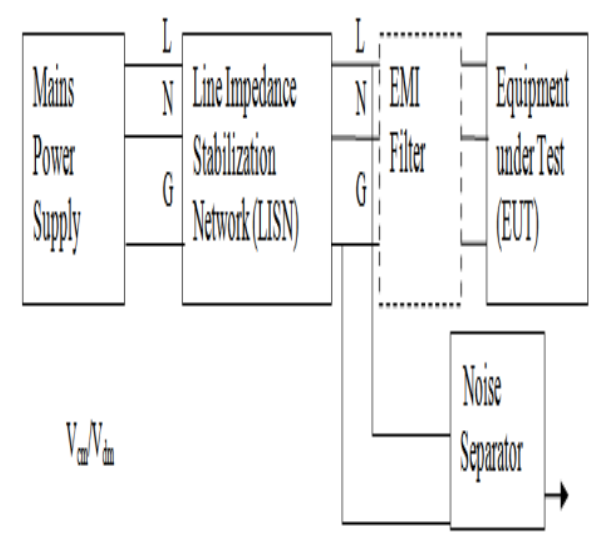

Figure 2: Conducted emissions measurement setup

\section{Line Impedance Stabilization Network (LISN)}

The conducted EMI measurement procedure requires a $50 \mathrm{~W} / 50 \mathrm{mH}$ Line Impedance Stabilization Network (LISN) to be inserted between the equipment under test (EUT) and the ac utility line to provide specified measuring impedance for noise voltage measurement. The basic schematic of LISN is shown in Figure3.

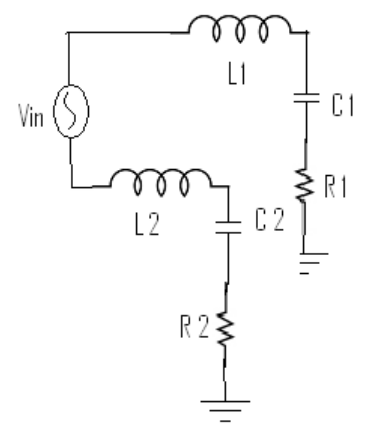

Figure 3: Schematic of LISN.

\section{Equipment Under Test (EUT)}

The EUT used in this setup is a 2transistor SMPS circuit that consists of two transistors, diodes which act as noise sources from which conducted EMI is generated.

\section{Noise Separators}

The common mode and differential mode noise from the measured output are separated using a noise separator DM noise rejection is done using a pssive circuit while an active circuit is used for CM noise rejection.

\section{Basic Emi Filters}

There are numerous EMI filters could be considered for noise reduction, but the most popularly used are the LC inductor filter and the $\pi$ filter for CM and DM noise respectively. The aim is to obtain the maximum impedance mismatch between the filter and the outside system.

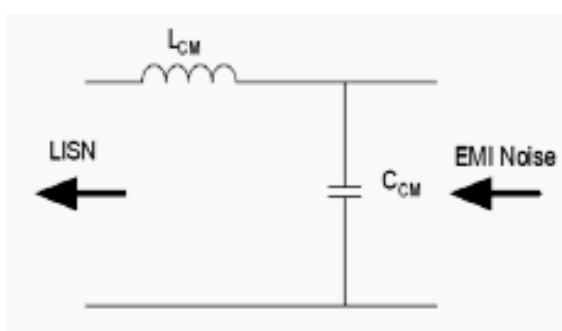

Figure 4: Inductor filter 


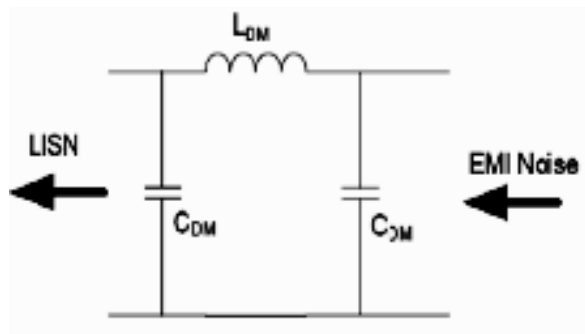

Figure 5: $\pi$ filter

\section{Emi Filter Design For Reducing Common-Mode}

A better solution over the inductor filter is the choke filter. Chokes withstand high DC currents without degradation of filtering performance. Chokes reduce noise considerably over the entire desired frequency range. The components of inductor filter are designed such that

If $\frac{1}{\mathrm{w}\left(2 \mathrm{C}_{\mathrm{cm}}\right)} \ll \mathrm{Z}_{\mathrm{P}}$, then

$$
\mathrm{W}\left(\mathrm{L}_{\mathrm{CM}}\right) \gg 25 \Omega
$$

Where $\mathrm{L}_{\mathrm{CM}}$ and $\mathrm{C}_{\mathrm{CM}}$ are inductor and capacitor used in the design of inductor filter and $\mathrm{Z}_{\mathrm{P}}$ is the impedance of the equipment used.

The components of $\pi$ filter are such designed such that

If $\frac{1}{\mathrm{~W}\left(\mathrm{C}_{\mathrm{DM}}\right)} \gg 100$ and

$$
\frac{1}{\mathrm{~W}\left(\mathrm{C}_{\mathrm{DM}}\right)} \ll \mathrm{Z}_{\mathrm{P}}, \text { then }
$$$$
\mathrm{W}\left(\mathrm{L}_{\mathrm{DM}}\right) \gg 100 \Omega
$$

Where $L_{D M}$ and $C_{D M}$ are inductor and capacitor used in the design of $\pi$ filter and $Z_{P}$ is the impedance of the equipment used.

\section{Simulation Results}

The circuit of bridge rectifier having the R load is drawn using the MATLAB is shown in which the distortion is available in the input voltage and current waveform.

A typical EM1 filter topology is used in the illustration in the paper, and the procedure has been experimentally verified in two switching power supply applications. The same procedure can be extended to other filter topologies, but this requires further work.

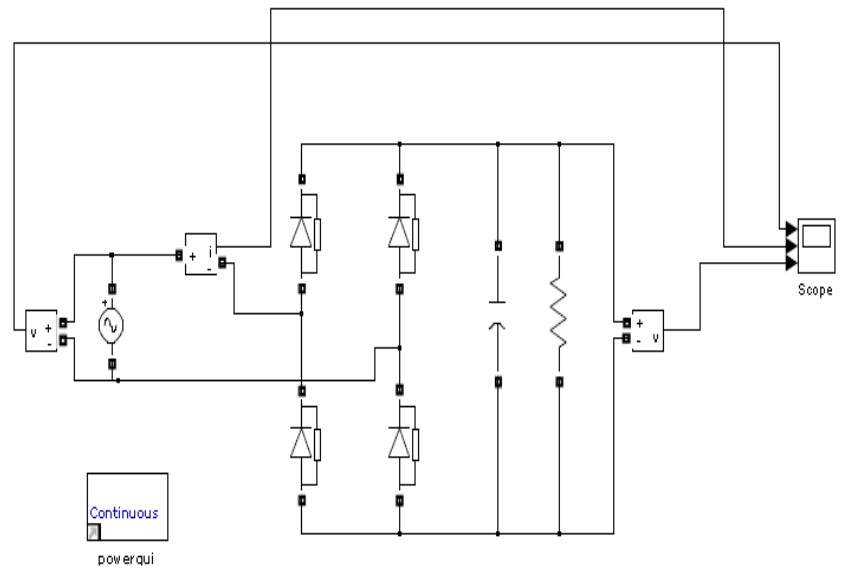

Figure 6: Simulink model of bridge rectifier without EMI filter 

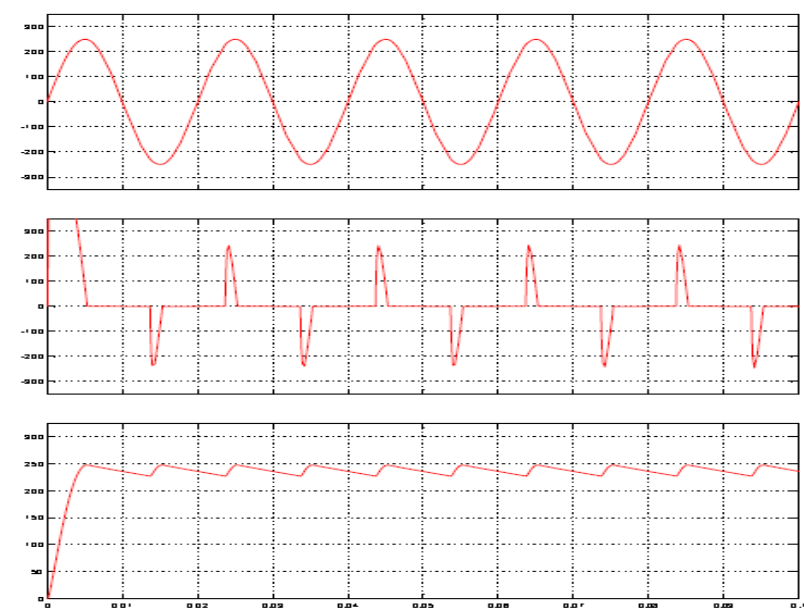

Figure 7: Result of Simulink model of bridge rectifier without EMI filter

The circuit with EMI filter is shown below in which the distortion is reduced with combining the bridge rectifier and inductor EMI filter.

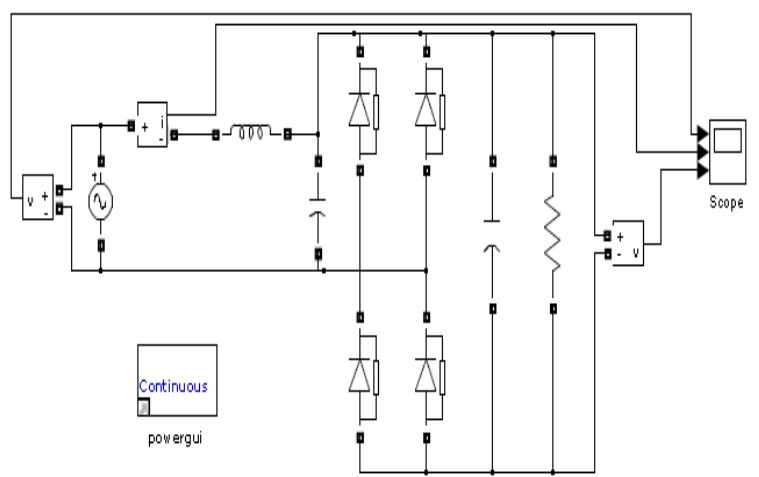

Figure 8: Simulink model of bridge rectifier with EMI filter
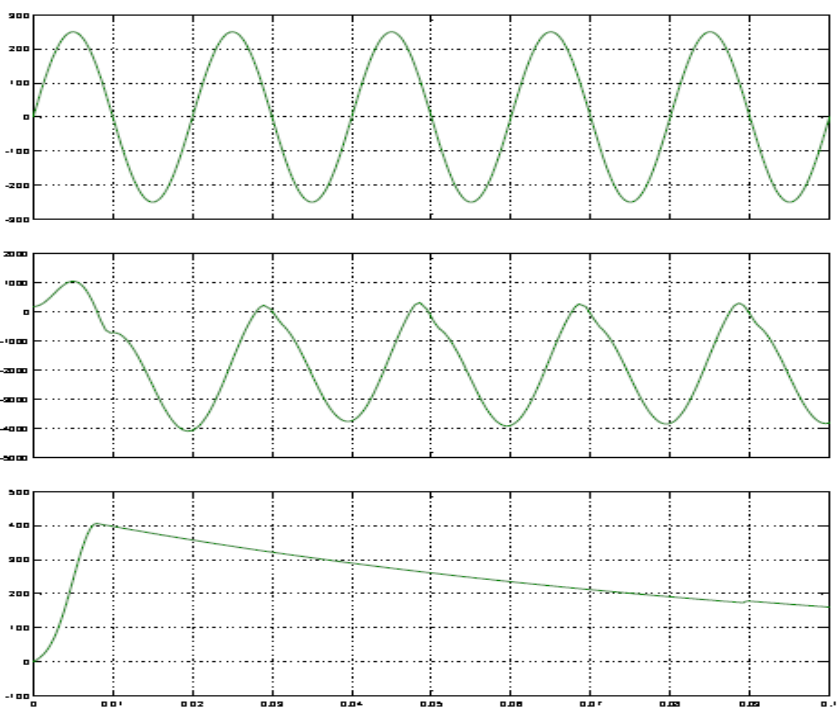

Figure 9: Result of Simulink model of bridge rectifier with EMI filter

\section{Conclusion}

A practical procedure for designing the EM1 filter is presented. This procedure leads to a quick filter design that at least meets the low-frequency part of design specification. Once designed and built, the filter may 
need slight modification to meet the high-frequency specification. This procedure facilitates the EM1 filter design process and greatly reduces cut-and-trial effort.

This paper implements inductor EMI filter for bridge rectifier. It is also used to reduce the boost power factor correction circuit. It differs from the conventional power factor correction techniques by eliminating inductor current sensing requirements. $\mathrm{C}_{\mathrm{CM}}$ mode is chosen which features smaller inductor current ripple resulting in low RMS currents on inductor and switch thus leading to low electromagnetic interference. By this technique supply current is made to follow supply voltage effectively. Thus the input power factor for diode bridge rectifier is improved and harmonic content in the supply current is reduced. It complies with standards for Total Harmonic distortion. In addition it also maintains output voltage regulation. All these together offer a satisfactory performance. Simulation results were presented for this technique which covers load variation also.

\section{References}

[1] Klaus Raggl, Thomas Nussbaumer, Johann W. Kolar "Guideline for a Simplified Differential-Mode EMI Filter Design" ieee transactions on industrial electronics, vol. 57, no. 3 march 2010.

[2] P. Ram Mohan, M. Vijaya Kumar, O .V. Raghava Reddy, "a novel topology of EMI filter to suppress common mode and differential mode noises of electromagnetic interference in switching mode power supplies", VOL. 2, NO., AUGUST 2007 ISSN 1819-6608 ARPN Journal of Engineering and Applied Sciences.

[3] Jukka-Pekka Sjöroos "Conducted EMI filter design for SMPS", Helsinki University of Technology, Power Electronics Laboratory. EMC Lab Info: www.emclabinfo.com

[4] Richard Lee Ozenbaugh, 2001, 'EMI Filter Design'.

[5] Maria Carmela Di Piazza, Member, IEEE, Antonella Ragusa, Member, IEEE, and Gianpaolo Vitale, Member, IEEE, "Design of Grid-Side Electromagnetic Interference Filters in AC Motor Drives With Motor-Side Common Mode Active Compensation", Ieee Transactions on Electromafnetic comoatibilty, Vol.51, No. 3, August 2009.

[6] Mel Berman, October 2008, "All about EMI filters", www.us.tdk-lambda.com.IMPACT - module 5, "conducted EMI/EMC", Indian institute of technology,new Delhi

[7] M. L. Heldwein, T. Nussbaumer; and J. W. Kolar, "Differential Mode EMC Input Filter Design forThree-Phase AC-DC-AC Sparse Matrix PWM Converters", Swiss Federal Institute of Technology (ETH) Zurich, Power Electronic Systems Laboratory, ETH Zentrum / ETL H23, Physikstrasse 3, CH-8092 Zurich, SWITZERLAND.

[8] O. Garcia, J. A. Cobos, R. Prieto, P. Alou, and J. Uceda, "Single Phase Power Factor Correction: A Survey," IEEE Trans. Power Electron., vol.18,no. 3, pp. 749-755, May

[9] Z. Yang and P. C. Sen, "Recent Developments in High Power Factor Switch Mode Converters," in Proc. IEEE Can. Conf. Elect. Comput.Eng., 1998, pp. 477-488.

[10] Haipeng Ren, Tamotsu Ninomiya, “The Overall Dynamics of Power-Factor-Correction Boost Converter”, IEEE, 2005.

[11] Huai Wei, IEEE Member, and Issa Batarseh, IEEE Senior Member,"Comparison of Basic Converter Topologies for Power Factor Correction, IEEE, 1998.

[12] Zhen Z. Ye, Milan M. Jovanovic and Brian T. Irving.’Digital Implementation of A Unity-Power-Factor Constant - Frequency DCM Boost Converter", IEEE, 2005

[13] A. Karaarslan, I. Iskender, "The Analysis of Ac-Dc Boost PFC Converter Based On Peak and Hysteresis Current Control Techniques, International Journal on Technical and Physical Problems of Engineering, June 2011.

[14] Wei-Hsin Liao, Shun-Chung Wang, and Yi-Hua Liu, Member, IEEE, "Generalized Simulation Model for a Switched-Mode Power Supply Design Course Using Matlab/ Simulink”, IEEE Transactions on Education, vol. 55, No. 1, February 2012.

[15] J. Lazar and S. Cuk, "Open Loop Control of a Unity Power Factor, Discontinuous Conduction Mode Boost Rectifier," in Proc. IEEE INTELEC, 1995,pp. 671-677.

[16] K. Taniguchi and Y. Nakaya, "Analysis and Improvement of Input Current Waveforms for Discontinuous-Mode Boost Converter with Unity Power Factor,” in Proc. IEEE Power Convers. Conf., 1997, pp. 399-404.

[17] Kai Yao, Xinbo Ruan, Senior Member, IEEE, Xiaojing Mao, and Zhihong Ye," Variable-Duty-Cycle Control to Achieve High Input Power Factor for DCM Boost PFC Converter", IEEE Transactions on Industrial Electronics, vol. 58, no. 5, May 2011. 